\title{
"Economics of Share-Cropping in Haryana (India) Agriculture" - Rejoinder
}

\author{
F. S. BAGI ${ }^{*}$
}

\section{INTRODUCTION}

Salam [18] raised a number of questions about my paper, and these can be briefly summarized here. (1) Inadequate description of sample. (2) Treatment of irrigated and unirrigated parts of a farm under same management as separate subfarms is questionable. (3) What prices have been used for farm products and byproducts consumed on the farm. (4) Many heterogeneous inputs have been aggregated together. (5) How the production expenditure presented in Table 3 has been estimated, and what wage rates have been used in these calculations? (6) Data presented in Table 2 and its interpretation are confusing and misleading. (7) The explanation provided for the relatively lower use of purchased inputs on share cropping farms (Table 5) is incorrect. (8) The estimation and discussion of returns to scale is redundant. (9) Some of the explanatory variables e.g. cropping intensity, number of fragments per farm, and managerial ability have been omitted from the model. (10) Operational size of farm is not an appropriate explanatory variable. (11) The effect of farm size on relative economic efficiency has been overlooked. (12) Aggregation of gross value of output for multicrop farms is likely to bias the results in an unknown direction, because crop composition may not be uniform across farms, and (13) Measurement of inputs in value terms are affected by prevailing market imperfections.

The data is described in the next section and it will answer the first two questions raised by Salam. The questions 3, 4, and 5 are discussed under, description of variables, in Section III. The points made in 6,7 , and 8 are clarified in Section IV: entitled redundant and misleading information. Section V is called, misspecification of the model, and points 9,10 , and 11 are discussed in this section. Section VI is named, relevance of farm-level production function, and the questions raised in 12 and 13 are discussed in detail in this Section; while brief concluding remarks are made in the last Section.

*Author is an agricultural economist with the Cooperative Agricultural Research Program and the department of Rural Development at Tennessee State University. 


\section{DESCRIPTION OF DATA}

The data has been collected by the Economic and Statistical Organization of Haryana under the composite programme of Economics of Agricultural Production and Farm Management Studies in the state. The survey covered all seven districts of Haryana, thus encompasing all the agro-climatic regions of the state. The design of sampling adopted was multi-stage stratified random sampling with the village as the primary unit and the holding as the ultimate unit. A total of 56 villages were selected randomly with probability proportional to net area cultivated. In the selection of villages the distribution of villages according to the nearest motorable (metal) road was also properly considered. In these 56 villages, 162 holdings were selected. While making selection of holdings it was ensured as far as possible, that the selected holdings should representative of the areas. Furthermore, the mode of irrigation and relative size of holdings in the district have also been kept in view.

Due to a variety of reasons, extensive inquiry probably being the most important, 43 holdings could not complete the full year of participation in the programme. Therefore, the remaining sample of 119 farms is not strictly random.

The data was collected throughout 1969-70 agricultural year. The recording of the data has been done under the Cost Accounting Method in the prescribed schedules. To ensure proper recording and accuracy of the data collected, frequent visits were paid by the inspectorate staff from headquarters and all the district statistical offices in the state. To enlist active cooperation of the selected cultivators for participating in the programme voluntarily, they were paid on honorarium.

Of the 119 holdings 20 were fully irrigated, 17 completely unirrigated and the remaining 82 were partly irrigated and partly unirrigated. Since the productivity as well as the cost of cultivation on irrigated and unirrigated lands differ considerably from each other, output and expenditure data for these holdings have been collected separately. Each crop from the irrigated and unirrigated parts of the same holding has been harvested and thrashed separately. Therefore, the data on the quantity of output, per hectare and yield and value of output for each crop on the irrigated and unirrigated parts of the holding is available. However, the data on inputs was not separately recorded for every crop on the both parts of a holding. Only the total quantity or value of input is available for the irrigated and unirrigated parts of the same farm. Therefore, the production functions for individual crops could not be estimated.

As the above description indicates, this data set is quite detailed, the sample has been selected on sound statistical grounds, and data has been collected quite carefully to ensure its reliability. Furthermore, these data have been very extensively analyzed by this author $[1 ; 2 ; 3 ; 4 ; 5 ; 6]$, and has found the data very rich in detail and reliable. The results drawn from its analysis can be generalized for the state of Haryana with reasonable confidence [5].
Salam objects to my treating the irrigated and unirrigated parts of the same 82 farms as separte irrigated and unirrigated sub-samples. One of his concerns is that I probably apportioned various inputs on these farms to the irrigated and unirrigated parts of these farms rather arbitrarily. But it should be now clear from the detailed description of the data, that separate records of every input actually used on the irrigated and unirrigated parts of every farm had been kept throughout the survey. Salam's concern about treating of sub-parts of a farm firm under the same management as separate parts is not quite reasonable. Such separation has actually been done to control the management factor. In other words, such separation helps to eliminate the effect of management abilities between the two samples, and the effect of other factors on the relative efficiency of two samples can be studied. Salam [18, p.451] himself suggests that the managerial ability (human capital) is an important variables in affecting the level of farm output and the economic efficiency. The proxies generally used for the managerial ability are level of formal education of the farm operator and other family members who influence the farming decisions, level of farming experience, age, contact with extension service, and other sources of technical information [15]. Such information could have easily been collected during the survey, but unfortunately it was neglected.

Since in my paper the major objective was to compare the economic efficiency of the share cropping and owner operated farms, the second best solution was to control the management factor. However, this could not be done for the sample of 119 farms, and 17 unirrigated farms. But it could be done to a great extent in the pooled sample of 201 farms, 102 irrigated, 99 unirrigated, and 58 irrigated and unirrigated share cropping farms. Actually, the basic reason for trying many different combinations of sub-samples was to minimize the difference in the management factor. However, it should be mentioned that this approach controls the management differences on the two parts of the same farm, while such differences across farms remain uncontrolled.

\section{DESCRIPTION OF VARIABLES}

In case farm product and/or its by -product was sold by the farmer, actual price received has been used, and the same price has been used for the portion of the product and/or its by-product used on the farm. But if farm product and/or its by-product was exclusively used on the farm, price(s) prevailing in the village under study during the harvest period has been used to compute gross value of output. Value of a farm by-product not sold by any one in the village was guessed. Fodders have been evaluated at the prices prevailing in the village. Value in this case has been determined for every individual field because the prices vary according to quality (i.e. condition, and stand) of a fodder crop. 
I agree with Salam's argument that disaggregated inputs provide more realistic and suitable results for policy prescription. However, data limitations have dictated the level of aggregation used in this study. Manure and fertilizer were lumped together because some of the farmers used either only fertilizer or manure. In the subsample of 102 irrigated farms, 20 farms used no manure while 19 used no fertilizer. Similarly, in the subsample of 99 unirrigated farms, 33 farms did not use manure, while 41 did not use any fertilizer. The flow of irrigation services has to be aggregated because in the subsample of 102 irrigated farms only 15 used Pershain Wheels, 18 did not have any access to canal water, and 48 were without tubewells or pumping sets. It should be mentioned here that the sources of irrigation are not the only factors which influence the effectiveness of irrigation. Bardhan [10, p. 1374] indicates that structure of soil also has an impact on irrigation's effectiveness. But level of rainfall is another major factor. Therefore, in future one should also collect information about rainfall, at least at the closest rainfall recording station, if not actually on the individual farm.

Miscellaneous expenses include any farm related expenses which have not been included in any of the above inputs. Only 23 farms have any miscellaneous expenses. The maximum miscellaneous expenses for one farm are Rs. 24.32, and the average expenses for all 23 farms are only Rs. 4.45. Land revenue is a very small item, therefore was also included in other expenses. Hence, for all practical purposes "other expenses" are just seed expenses. There is an error on page 109. It should read - other expenses include actually paid and imputed value of seeds, land revenue, and miscellaneous expenses. Therefore, it is not land rent, rather it is revenue which has been included in "other expenses".

Wages of permanent farm labourers include payments made in cash and/or kind and/or other perquisites. The value of payments made in kind has been calculated at harvest prices, since such payments are made soon after crop harvest. Among perquisites the consumption of food has been estimated at $40 \mathrm{kgs}$. of foodgrains per month at harvest prices of the preceding year in case the food was provided from the home produce, otherwise actual prices incurred on the purchase of such foodgrains. In case of other perquisites like clothes, shoes, bedding, etc., amounts actually spent on such goods have been used. In case residential accommodation has also been provided for the permanent labourer, the rental value of such accommodation is also charged at the prevailing rental rates in the village.

Thus calculated wage rate for the permanent labourer on the selected holdings in the village has been used for the family workers. In case no such permanent labourer was employed by any of the selected cultivators in the selected village, the prevailing wage rate for the casual farm labour was used for the family labour. The wages for the casual farm labourer consists of actual amounts paid in cash and/or the value of kind payments at the prevailing prices. The value of the meals, tea, tobacco, etc. has also been included for each holding separately according to actual quantity of the perquisites supplied.
Since share croppers use more labour per hectare, Salam [18] is correct in observing that this may account for relatively lower net income on share cropping farms. The share croppers in our sample also own their own land, and in general the area share cropped is much smaller as compared to the area owned by these farms. Furthermore, all farms have used some permanent and/or casual labour. Therefore, there is little reason to believe that the opportunity cost (i.e. shadow wage rate) of a share cropper's family labour should be less than that of the pure owner operator Salam [18] seems to suggest that the opportunity cost of the farm family labour is even lower than the wage rate paid to the hired (permanent or casual) labour. His argument may have some validity because the farm family workers may be unwilling to hire out their labour to other farmers in the village [6]. However, the opportunity cost of the family labour for the two groups of farms is likely to be quite similar. Therefore, even if the actual opportunity cost is lower than the prevailing agricultural wage rate, the net income on share cropping farms will still be relatively lower, because they use more labour.

\section{REDUNDANT AND MISLEADING INFORMATION}

Salam [18] says that small farmers engage in share cropping in order to supplement their meagre incomes from their own small holdings, and he complains that I have ignored income from share cropping operation since I have compared the income from owned area alone in Table 2. Unfortunately, he has overlooked the explanation provided in my paper. Actually, the one and only reason for presenting Table 2 was to show that the share-croppers have insufficient income from their owned area, and they engage in share-cropping to generate additional income in order to achieve an adequate living standard [2, p. 100].

There is an error in Table 5. In the first row, output is actually measured in wheat equivalent quintals. Therefore, in the parentheses, it should read quintals instead of rupees. A footnote should have been added to explain the calcualtion of wheat equivalent quintals of output. The total value of crops and crop by-products has been divided by the wheat price actually received by the individual farms. Wheat was chosen because every farm in the sample had grown wheat, and it constituted major portion of farm income.

It is also true that the differences in the output and input levels of the owner operated and share cropped farms were not statistically tested. The statistical tests would have established the validity of the comparison. However, these differences especially in the levels of purchased inputs are rather obvious.

Salam [18] suggests that the lower use of purchased inputs on the share cropping farms can be attributed to imperfect factor markets, ignorance about the usefulness of these inputs, and uncertainty of share-cropping contracts. It is possible that these factors may have significant effect on the level of purchased inputs used. 
However, it is quite reasonable to assume that an increased participation in purchased inputs by the landlords is likely to moderate the impact of these factors. Furthermore, increased use of purchased inputs is likely to increase output and hence, it is mutually beneficial for both landlord and the share cropper [11;13]. A number of sub samples were used to estimate returns to scale, because the main objective was to test whether constant returns to scale prevail or not. Some of the samples were not used for analysis of economic efficiency. Of course, we could have calculated returns to scale from equation (2). But there is an important reason to estimate both equations (1) and (2). This approach enables to test the specification of the equation and consistency of the estimated coefficients. It was this approach which enabled me to determine that cropping intensity is not a logical explanatory variable in the model [7]. Therefore, the section on returns to scale is not redundant.

\section{MISSPECIFICATION OF THE MODEL}

Unfortunately, no information was collected on the number of land parcels and the distance between the main farm building and each parcel. Therefore, it was not possible to study its effect on production efficiency. However, as Salam points out it is likely that share croppers in general may have to cultivate more parcels than the owner operators. Therefore, it may contribute significantly to the economic inefficiency of the share cropping farms. But an inclusion of this variable is only likely to identify the source of inefficiency, and may even improve $R^{2}$ value, but there is little reason to believe that it will increase the relative technical efficiency of the share-cropping farms. Similarly, data about the managerial abilities has not been collected, and hence could not be explicitly included in the model.

Technical efficiency is defined as the ability to produce maximum output from a given bundle of inputs [19]. In the absence of any legal restrictions on the use of land, the level of cropping intensity is a function of the quality of land, availability of complementary inputs, and farmer's managerial ability to choose and combined different rotations which maximize output without deteriorating the quality of land. In other words, cropping intensity is a function of factors of production and the managerial ability of the farmer. Hence, is correlated with other explanatory variables. I have shown empirically that cropping intensity is not an appropriate explanatory variable for this data set, and have further shown that Bardhan's [10] estimates are also biased because he included cropping intensity as an explanatory variable [7].

Salam [18] thinks that using operational size, without incorporating cropping intensity as explanatory variable, implicitly assumes 100 percent cropping intensity. That is not correct. In a very crude way one can say that it assumes equal cropping intensity across farms. But in reality, all it assumes is that quality of land is the same across farms. It should be mentioned here that standard production functions make two important implicit assumptions. First, the quality of each factor of production is the same across farms. Second, the same technology is available to all farms. Obviously, these are rather serious assumptions.

In the absence of government control over land use on individual farms, the operational size of farm is a more appropriate variable than net or gross cropped area. If at all possible, operational size may be adjusted for quality of land, which is not quite easy [10, p.1374]. Sidhu and Baanante [20] have used the actual soil tests on the $\mathrm{N}, \mathrm{P}, \mathrm{K}$, content of soil and its $\mathrm{pH}$ level. Information on $\mathrm{pH}$ level is important because at abnormal levels of $\mathrm{pH}$ yields of most crops are adversely affected. It will still be difficult to develop an aggregate measure of $\mathrm{pH}$ for the farms as a whole $\mathrm{pH}$ level may vary across individual fields on a given farm. Information on $\mathrm{N}, \mathrm{P}, \mathrm{K}$, content of soil is important, but it will again suffer from aggregation on farm level. However, further important classifications of land are possible. For example, clay loam and sandy loam soils may be relatively less suitable for most of the crops as compared to loam soil. But clay loam is relatively more suitable for rice production than loam and sandy loam soils. On the other hand, sandy loam soil is more suitable for groundnut (peanut) and cotton production as compared to loam and clay loam soils. Therefore, information on N, P, K, content of soil may be less useful if there is great intra- and inter-farm variation in soil (i.e. clay loam, loam, and sandy loam, etc.). Information on soil structure, fertility, and $\mathrm{pH}$ level should be collected for individual fields on a given farm. Aggregation problems in constructing such indices will be greatly reduced when production functions for individual crops can be estimated. Farm Management studies have been emphasizing the need for similar information since long.

The major objective of my study was to compare the economic efficiency of share cropped and owner operated farms, and this analysis alone is fairly large. The analysis of the effect of size on the economic efficiency would have reduced the clearity of purpose and increased the size of the paper. (It should be noted however, that I have successfully incorporated the effect of irrigation on economic efficiency.) Using the same data I have analyzed the effect of size on economic efficiency elsewhere $[4 ; 5 ; 6]$. The results show that technical efficiency is higher on the small farms, while neither group has definitive advantage in allocating every input. Table 1 in my original paper showed that on the basis of owned area alone share-cropped farms are smaller than pure owner operated farms. But it also showed that some farms even with relatively large owned area engage in share-cropping. Furthermore, on the basis of operational size of the holding (which includes owned, cash rented, and share-cropped area) few more share-cropped farms are likely to be classified as large farms. However, in order to isolate the effect of size on efficiency one needs to control the effect of tenure. In other words, the share-cropping farms themselves should be divided into small and large farms, and then compared the economic efficiency of the two sub-samples. Similar analysis should be performed for the 
owner operated farms. But there are only 34 share cropping farms and their further classification into small and large farms will not leave enough observations in each category.

Intensity of irrigation, proportion of area under high yielding varieties [19] level of mechanization, and differences in managerial abilities [15] are other important factors which affect the level of economic efficiency. Therefore, in the strict sense one needs to control the effect of size, irrigation, seed technology, mechanization, and managerial abilities, before one can compare the economic efficiency of the share-cropped and owner operated farms. Such analysis would require very large sample and very detailed input and output data separately recorded for each and every sub-sample. Furthermore, it will be extremely difficult and expensive to collect such data. However, recent developments in the area of stochastic frontier production functions have made it possible to estimate the separate contribution of every such factor to the technical and allocative efficiency $[9 ; 14]$.

\section{RELEVANCE OF FARM-LEVEL PRODUCTION FUNCTION}

There is well known controversy about the existence of aggregate production functions [8] . Here Salam [18] is referring to another controversy - whether or not even farm-level production functions exist [10]. Bardhan [10] suggested that in order to avoid this aggregation problem at the farm-level it would be preferable to concentrate on farms in nearly monocrop regions or on cropwise prodction where input and output data are available separately for each crop [10, p.1375]. Sahota [16] and Salam [17] have estimated the individual crop production functions. Where input and output data are available separately for each crop, the estimation of unique production functions for individual crop and livestock enterprises will be the best approach to follow. This approach is important for two reasons. First, one does not have to aggregate heterogeneous output. Second, unique production functions for individual crop and livestock enterprises can be estimated, because each enterprise production function may have a unique functional form as has been demonstrated by Salam [17]. Furthermore, the technical and allocative efficiency may differ from crop to crop for the same group of farms.

In our case, unfortunately, separate input data for every crop enterprise is not available. Therefore, the only available alternative was to aggregate the value of heterogeneous crop outputs. This implicitly assumes that crop composition is similar for all farms [10, p.1374-75]. But data presented in Table 4 in my paper [2] suggests that this assumption does not hold in its strict sense for all 34 share cropped and 85 owner operated farms. However, it should be mentioned that both groups of farms grow the same crops, although there is difference in the relative area under each crop among the two groups of farms. Furthermore, it is well known from programming studies that due to the differences in the resource levels of individual farms, an optimal solution to the profit maximization function generally shows different areas under different crops on individual farms. Therefore, even if the crop composition is not exactly the same, one could still assume that, in case both groups of farms face similar input and output markets, the observed crop composition represents optimal enterprise combinations on individual farms. But in our case even this second best assumption may be violated because the landlord generally has more say as to what crop(s) may be grown on the share-cropped area. Therefore, the share-cropping farms may face this additional limitation. However, it is plausible to assume that the landlords will be in favour of growing high value crops, and this may not have any significant adverse effect on the share cropping farms.

Our data shows that there is variation in both prices received and paid by the farmers in the sample. The difference in the quality of outputs produced and inputs used is the most important reason for such price variations across farms. Therefore, the use of quantity measure will ignore these qualitative differences. Prices actually received and paid in the market places adequately reflect such quality variations in outputs and inputs across farms. Given the price variations across farms are primarily due to qualitative differences, the value measure will provide more realistic estimates of relative efficiency. This strongly suggests that even if detailed output and input data are available in physical quantities for every crop separately, it is important to adjust them for qualitative differences. As mentioned before, standard production functions assumes constant quality of inputs across farms. Obviously the value measure of inputs assumes that the prevailing input prices are the same for all farms for the same quality of inputs. However, as Salam [18] points out that due to market imperfections, all farmers may not face the same configuration of input prices for the same quality inputs. It is little difficult to claim that the agricultural markets are perfect even in the developed countries what to say of developing countries. But Haryana markets are reasonably well developed. Whatever imperfections are there, cause the same problems for all farmers, and there is hardly any reason to believe that they are biased towards share croppers or owner operators.

Furthermore, the assumption of constant quality of inputs across farms is more serious than that of equal price. Since, quality of inputs is likely to vary across farms, the value measure of inputs is more appropriate as compared to the quantity measure. An extreme example of qualitative diversity is farm yard manure. The one produced on the farm is likely to have fairly high content of dung, while the one purchased from landless families generally consists of dirt, dry grass and ashes. The crop nutrients of the two types of manure obviously are not the same, and a quantity measure will be grossly misleading, while a value concept is likely to reflect the quality of this input. Of course, the best alternative will be to use the quantity of plant nutrients in the manure. But it will require a sample analysis of every source of manure available to a given farm. Even for fertilizer one needs to use measure(s) 
of plant nutrients because the nutrient content of every commercial brand of fertilizer is different, and farmers use different fertilizers (i.e. N, P, K) in different proportions. Furthermore, they use different commercial brands of Nitrogeneous fertilizers, which have different Nitrogen content per Kilogram of fertilizer.

\section{CONCLUDING REMARKS}

There are only few remarks made by Salam [18], which specifically apply to my paper, and other comments are general and can be directed at almost any empirical production function study based on farm-level data. His all general objections primarily amount to saying that aggregating heterogeneous outputs and inputs is invalid. Since the estimation of a farm-level production function generally uses an aggregate of heterogeneous outputs from a number of farm enterprises, farmlevel production function is an inappropriate concept. He also suggests that every individual input should be treated as a separate independent variable.

However, the conceptual problems are more complicated than Salam [18] realizes. Farm-level production function as well as individual crop (enterprise) production functions make two important implicit assumptions. First, the quality of every output and input is the same across farms. Second, the same technology is available to all farms. Therefore, it is necessary to develop appropriate measures of technology actually available to individual farms, but it may not be easy. Furthermore, it is necessary to explicitly account for qualitative differences in outputs and inputs across farms. It has been shown in this rejoinder that the qualitative differences in an input (e.g. land) may be caused by more than one factor. This complicates the process of standardizing the quality of an input. This indicates that one needs to collect not only output and inputs data separately for every farm enterprise, but also on all qualitative aspects of every output and input. This is not any revelation. Farm Management researchers have been collecting and using similar data since long.

Salam [18] reiterates a common suggestion in the literature that it is preferable to use physical measures of output as well as inputs. But I have indicated that a physical measure must be adjusted for qualitative differences. Furthermore, if variations in output and input prices across farms reflect primarily the qualitative differences, then using a value measure will be more appropriate. It is true that estimating separate production functions for individual farm enterprises, using detailed data for every input, will provide detailed and useful information. But in the absence of such detailed data, it seems reasonable to aggregate inputs which are substitutes for each other (e.g. manure and fertilizers). Furthermore, if all farmers in the area face similar input and output markets, and price variations primarily reflects qualitative differences in outputs and inputs across farms, estimating a farm-level production function may provide quite reasonable results.

\section{REFERENCES}

1. Bagi, F. S. "Economic of Irrigation in Crop Production in Haryana". Indian Journal of Agriculture Economics. Vol. 36, No. 3. July-September 1981.

2. Bagi, F. S. "Economics of Share-Cropping in Haryana (India) Agriculture". Pakistan Development Review. Vol. XX, No. 1. Spring 1981. pp. 95-119.

3. Bagi, F. S. "Irrigation, Farm Size, and Economic Efficiency: An Analysis of Farm-Level Data in Haryana (India) Agriculture". Artha Vijnana. Vol. 23, No. 2. June 1981.

4. Bagi, F. S. "Relationship Between Farm Size and Economic Efficiency: An Analysis of Farm-Level Data from Haryana (India)". Canadian Journal of Agricultural Economics. Vol. 29, No. 3. November 1981.

5. Bagi, F. S. "Economic Evaluation of Some Agrarian Policies: The Case of Haryana, India". Forthcoming in Economic Development and Cultural Change.

6. Bagi, F. S. "Relationship Between Farm Size, Productivity, and Returns to Scale in Haryana Agriculture". Forthcoming in Economic and Political Weekly.

7. Bagi, F. S. "On Estimating the Cobb-Douglas Production Function". Forthcoming in the Indian Journal of Economics.

8. Bagi, F. S., and S. K. Bagi. "Aggregate Production Function and Marginal Productivity Theory of Distribution”. Indian Economic Journal. Vol. 28, No. 4. April-June 1981.

9. Bagi, F. S. and C. J. Huang. "Estimating Technical Efficiency Relative to a Variable Stochastic Production Frontier". Forthcoming in the Oxford Economic Papers.

10. Bardhan, P. K. "Size, Productivity, and Returns to Scale: An Analysis of Farm-Level Data In Indian Agriculture". Journal of Political Economy. Vol. 81, November-December 1973. pp. 1370-1386.

11. Bardhan, P. K., and Ashok Rudra. "Terms and Conditions of Share-cropping Contracts: An Analysis of Village Survey Data in India". Journal of Development Studies. Vol. 17, 1980. pp. 287-302.

12. Barnum, H. N., and Lyn Squire. "Technology and Relative Economic Efficiency”. Oxford Economic Papers. Vol. 30, No. 2. July 1978. pp. 181-198.

13. Bell, Clive. "Alternative Theories of Share-Cropping: Some Tests Using Evidence from Northeast India". Journal of Development Studies. Vol. 13. July 1977 . pp. 317-346.

14. Huang, C. J., and F. S. Bagi. "Stochastic Frontier Production Function and Average Efficiency in Indian Agriculture". Working Paper No. 80-W25, Department of Economics and Business Administration, Vanderbilt University, October 1980. 
15. Muller, J. "On Sources of Measured Technical Efficiency: The Impact of Information". American Journal of Agricultural Economics. Vol. 56, No. 4. 1974. pp. 730-738.

16. Sahota, Gian Singh. "Efficiency of Resource Allocation in Indian Agriculture". American Journal of Agricultural Economics. Vol. 50, No. 3. August 1968. pp. 584-605.

17. Salam, Abdul. "Resource Productivity in Punjab's Agriculture". Pakistan Development Review. Vol. XV, No. 2. Summer 1976.

18. Salam, Abdul. "Economics of Share-Cropping in Haryana (India) Agriculture" A Comment. Pakistan Development Review. Vol. XX, No. 4. Winter 1981.

19. Schmidt, P., and C. A. K. Lovell. "Estimating Technical and Allocative Inefficiency Relative to Stochastic Production and Cost Frontier". Journal of Econometrics. Vol. 9, 1979. pp. 343-366.

20. Sidhu, Surjit Singh, and Carlos A. Baanante. "Estimating Farm-Level Input Demand and Wheat Supply in the Indian Punjab Using a Translog Profit Function”. American Journal of Agricultural Economics. Vol. 63, No. 2. May 1981. pp. 237-246. 